\title{
AUTORIDADE LOCAL E O GENOCÍDIO DE RUANDA DE 1994: $O$ caso do Burgomestre Jean-Paul Akayesu
}

\section{LOCAL AUTHORITY AND THE RWANDAN GENOCIDE OF 1994: The case of the Bourgmestre Jean-Paul Akayesu}

Danilo Ferreira da Fonseca*

\begin{abstract}
RESUMO: O presente artigo visa refletir acerca do lugar que os políticos ruandeses vinculados às pequenas administrações locais, principalmente às comunas, possuíram frente à organização e à execução do genocídio de Ruanda em 1994. Para tal, construímos uma análise a partir de um estudo de caso vinculado ao Burgomestre Jean-Paul Akayesu, o qual administrava a Comuna de Taba (prefeitura de Gitarama) no período anterior e durante o genocídio. A análise é construída principalmente a partir do documento produzido pela Tribunal Penal Internacional para Ruanda (ICTR, da sigla em inglês) intitulado The prosecutor versus Jean-Paul Akayesu - Case No. ICTR-964-T, de 1998. Desta forma, busca-se dimensionar também os efeitos nefastos que o colonialismo belga realizou em um processo de colonização mental.
\end{abstract}

PALAVRAS-CHAVE: Ruanda. Genocídio. Akayesu.

ABSTRACT: This article aims to reflect on the place that Rwandan politicians linked to the small local administrations, mainly the communes, possessed before the organization and execution of the genocide of Rwanda in 1994. To this end, we constructed an analysis from a case study linked to the burgomaster Jean-Paul Akayesu, who administered the commune of Taba (prefecture of Gitarama) in the previous period and during the genocide. The analysis is constructed mainly from the document produced by the International Criminal Tribunal for Rwanda (ICTR) entitled The prosecutor versus Jean-Paul Akayesu - Case No. ICTR-96-4-T, 1998. In this way, the aim is also to assess the harmful effects of Belgian colonialism in a process of mental colonization.

KEYWORDS: Rwanda. Genocide. Akayesu.

\section{Considerações iniciais}

Entre abril e junho de 1994, Ruanda passou por um dos mais brutais genocídios do século XX. Em pouco mais de cem dias, algo em torno de 500 mil e um milhão de ruandeses foram assassinados, sendo que a maioria das vítimas se compunha de Tutsis e de Hutus que eram tidos como "moderados". O genocídio de Ruanda fica ainda mais impactante dentro da história recente se tivermos em mente que uma parte considerável dos assassinatos foi realizada por cidadãos comuns e a partir de golpes de facões - ferramenta muito utilizada no trabalho rural do país.

Este complexo episódio do mundo contemporâneo passa muitas vezes por análises rasas, em que uma concepção etnocêntrica de cunho europeísta subsome a pluralidade da história recente de Ruanda e de todo o continente africano, tornando os conflitos internos

\footnotetext{
* Professor da Universidade Estadual do Centro-Oeste (Paraná), lotado no Departamento de História do Campus de Irati/PR. É Doutor em História Social pela Pontifícia Universidade Católica de São Paulo (PUC-SP), com a tese Etnicidade e lutas de classe na África contemporânea: o África do Sul (1948 - 1994) e Ruanda (1959 1994). Contato: daniloffonseca@gmail.com
} 
dessa territorialidade como sendo fruto de uma mera barbárie, da não civilização, em que seus sujeitos históricos seriam incapazes de mediar conflitos para além da esfera da violência. Toda essa concepção histórica e historiográfica é corroborada inclusive com uma indústria cultural massiva que constantemente representa o sujeito histórico africano como um ser que possui na violência o seu principal modo de mediação.

Frente a um episódio como ao genocídio ruandês, em que encontramos um padrão de assassinato e discurso de ódio étnico, somados à ampla participação popular, é bastante comum encontrarmos análises acadêmicas que contribuem com essa concepção, subsumindo a complexidade do sujeito histórico ruandês, o que o deixa privado de ser ativo em sua própria história.

Na obra Murambi: le livre des ossements, publicada pela primeira vez em 2000, o novelista senegalês Boubacar Boris Diop escancara o caráter etnocêntrico que o genocídio de Ruanda assume frente a alguns analistas e também frente à reação internacional, ainda mais em um contexto em que:

A Copa do Mundo estava para começar nos Estados Unidos. O planeta estava interessado em nada mais. $E$ de qualquer forma, o que acontecesse em Ruanda, seria sempre a mesma velha história de pretos batendo uns nos outros. Até mesmo africanos diriam, no decorrer dos intervalos de cada partida, "eles estão nos constrangendo, eles deveriam parar de matar uns aos outros assim. ${ }^{102}$ (DIOP, 2006, p. 9).

No presente artigo, buscamos entender o processo ruandês de uma maneira ampliada, valorizando as especificidades locais somadas às inserções globais em um contexto mais amplo que podemos encontrar no século XX. Nesse sentido, não podemos compreender o genocídio de Ruanda como um evento ou um momento de exceção, ou que fugisse à regra dentro da sociedade contemporânea, mas sim como o seu próprio funcionamento, assim como apontou Walter Benjamin.

Walter Benjamin ajuda a perceber que a tarefa de um historiador é sempre de "escovar a história a contrapelo" (BENJAMIN, 1993, p. 225), procurando as evidências que não corroboram com o "continuum da história", ou com a história dos vencedores, pois este continuum faria com que "o 'estado de exceção' em que vivemos seja a regra geral" (BENJAMIN, 1993, p. 226). O entendimento de que o mundo contemporâneo vive uma crise constante, e não diversos momentos de exceção, é de fundamental importância para se entender a história de Ruanda.

Ao destrincharmos o genocídio e a história ruandesa com uma maior clareza, podemos observar que o processo de 1994 não se configura como uma "caixa de pandora da barbárie", mas sim como um complexo processo que foi possível somente a partir de uma ampla organização propagandística, burocrática e logística.

Já com a colonização belga, podemos identificar aspectos que corroboraram com o desenvolvimento do genocídio em 1994, principalmente no que tange ao desenvolvimento das identidades Tutsis e Hutus, em processo de racialização somente possível com uma articulação entre a elite local e os colonialistas belgas, em uma forma de colonização mental, conforme desenvolve Frantz Fanon (2005).

Já enquanto um país independente, mas repleto de amarras políticas e econômicas, no final da década de 1980 e início de 1990, foi bastante comum encontramos meios de comunicação, principalmente rádios e revistas, que publicitavam um discurso de ódio contra os Tutsis, reforçando uma ideologia voltada para o extermínio. No que diz respeito à organização burocrática, podemos observar que a concretização do genocídio possuiu uma

\footnotetext{
102 No original: "The World Cup was about to begin in the United States. The planet was interested in nothing else. And in any case, whatever happened in Rwanda, it would always be the same old story of blacks beating up on each other. Even Africans would say, during half-time of every match, "they're embarrassing us, they should stop killing each other like that". (Tradução livre).
} 
rígida hierarquia de "trabalho" por parte dos perpetuadores ${ }^{103}$, que trouxe uma maior eficiência na produção do extermínio.

Dentro dessa logística da execução do genocídio, o estudo de Scott Straus na obra The order of genocide (2006) permite perceber que uma parte considerável dos perpetuadores do genocídio que estavam coordenando as ações genocidas compunha-se de sujeitos que ocupavam cargos na máquina burocrática do Estado, como é o caso de Burgomestres, conselheiros, membros de partidos políticos, agentes governamentais etc. (STRAUS, 2006, p. 106). Dentre os perpetuadores que não eram agricultores, aqueles que tinham como primeira ocupação uma função ligada ao governo e à sua burocracia representaram quase 50\% dos perpetuadores do genocídio (STRAUS, 2006, p. 106).

A partir de tal constatação, o presente artigo visa refletir sobre o papel da administração pública e da estrutura estatal de poder que corroborou e permitiu o genocídio em 1994. O foco recai sobre um sujeito específico: Jean-Paul Akayesu, Burgomestre da Comuna de Taba (na prefeitura de Gitarama) no decorrer do genocídio. Para tal, temos como suporte o documento final do julgamento realizado pelo Tribunal Penal Internacional para Ruanda (ICTR, da sigla em inglês), mais especificamente o caso ICTR-96-4-T The prosecutor versus Jean-Paul Akayesu de 1998.

O documento em foco foi obtido a partir de um levantamento dos bancos de dados on-line disponíveis no sítio da Organização das Nações Unidas específico para o Tribunal Penal Internacional para Ruanda. ${ }^{104} \mathrm{O}$ caso de Jean-Paul Akayesu foi o primeiro a ser julgado pelo Tribunal em 1998 e corresponde a um início de esforço para o julgamento para os crimes ocorridos em Ruanda. O processo de Akayesu aponta para caminhos que outras dezenas de processos seguiram nos anos decorrentes e que serão analisados em outras publicações. ${ }^{105}$ Os relatos de testemunhas presentes em tais processos possibilitam raros momentos de contato com a experiência daqueles que vivenciaram o genocídio de Ruanda, tornando tais documentos ricos em possibilidades de análise histórica.

Com esta análise, pretendemos esclarecer o papel da política local no genocídio de 1994, indo além de estudos que focam principalmente em políticos do primeiro escalão do governo ruandês do período estudado. No presente estudo, nos aprofundamos no caso do Burgomestre Jean-Paul Akayesu mas antes precisamos trazer algumas considerações sobre o genocídio de 1994 em Ruanda e a construção da história recente de Ruanda.

\section{O genocídio Ruandês de 1994 e a história recente de Ruanda: algumas considerações}

O território que hoje é Ruanda foi um dos últimos territórios africanos a entrar em contato com a sociedade ocidental. Até meados do século XIX, a sociedade Banyarwanda possuía relações comerciais e culturais com seus vizinhos mais próximos, mas permaneceu distante das principais rotas transcontinentais, seja nas trocas índicas, atlânticas ou transaarianas.

O entendimento do funcionamento da sociedade Banyarwanda é fundamental para compreendermos a história contemporânea de Ruanda, tendo em vista que muito das práticas sociais e visões de mundo da sociedade ruandesa vem de seus costumes enquanto Banyarwandas. Os Banyarwandas se constituíram enquanto uma fechada sociedade no território que hoje é Ruanda e sua formação social era baseada em divisões de castas, assim como muitas sociedades domésticas do continente africano (BELLUCCI, 2010, p. 14). Estas castas eram baseadas no ofício de seus componentes, sendo que aqueles que eram pecuaristas eram denominados de Tutsis e os que eram agricultores eram denominados como Hutus (MAMDANI, 2002, p. 61). No entanto, é importante destacar que tais

\footnotetext{
103 Termo utilizado para definir aqueles que corroboraram com a perpetuação do genocídio.

104 Disponível em:<http://unictr.irmct.org/>.

$105 \mathrm{O}$ presente artigo se insere num esforço mais amplo de análise da política local ruandesa, em que processos de outros Burgomestres também estão em análise a partir de um projeto de pesquisa individual vinculado à Universidade Estadual do Centro-Oeste (UNICENTRO). Espera-se obter resultados mais amplos ao cruzar dados e análises de outros burgomestres que participaram do genocídio de Ruanda.
} 
classificações não eram rígidas e poderiam mudar de acordo com a ascensão/decadência financeira ou social de um determinado indivíduo.

Essa divisão baseada no ofício também influenciava a própria formação política dos Banyarwandas, em que a população Tutsi (que se constituía como uma minoria) possuía o domínio político e os Hutus possuíam funções mais voltadas apenas para o trabalho. Essas divisões eram entendidas como legítimas, tendo em vista que eram validadas pelos próprios costumes e obrigações postos para cada grupo. Dentre tais costumes, é importante destacar o Ubuhake, que correspondia a um compromisso político a ser assumido frente a um superior ou soberano no âmbito da hierarquia interna de Ruanda (MAMDANI, 2002, p. 65). Tal rede de compromissos se estendia por praticamente todo o país e tinha como a principal figura um soberano denominado Mwami, que seria uma forma de monarca da região.

A vida dos Banyarwandas tomou um rumo bastante distinto com a chegada de grupos missionários europeus em seu território no final do século XIX e no início do século XX. No entanto, a população local não se mostrou muito aberta aos estrangeiros, mantendo seus costumes sólidos, ainda mais com a resistência do Mwami Yuri IV, que relutava em abrir e ampliar as relações com os europeus. Diante da administração colonial belga, que assumiu o poder do território ruandês, as correlações políticas e sociais dos Banyarwandas mudaram de maneira significativa. A resistência de Yuri IV frente às mudanças propostas pelos belgas (e até de parte da sua corte) fez com que este fosse envenenado e que, em seu lugar, assumisse seu filho, Mutara III.

O domínio do Mwami Mutara III causou mudanças profundas na sociedade Banyaruanda na década de 1930, tendo em vista que levou a cabo reformas desejadas pelos colonizadores e por parte da elite local (FONSECA, 2015, p. 119). Durante os anos da década de 1930, o novo Mwami corroborou que Ruanda se tornasse um território oficialmente cristão, com uma nova organização de seu mundo do trabalho e também com uma nova divisão entre Tutsis e Hutus, já que estes deixaram de ser castas baseadas em ofícios, que poderiam ser alteradas, para se tornarem grupos raciais baseados pelo nascimento. Com isso, cada ruandês precisaria carregar uma carteira de identificação racial (na qual era apontada se esse sujeito era Tutsi ou Hutu), que permaneceu válida mesmo com a independência e foi abolida somente após o genocídio em 1994.

É importante deixar claro que esse projeto levado a cabo em Ruanda fazia parte de uma articulação política entre a elite local e o poder colonial belga e que proporcionou uma colonização mental da população local, na medida em que foram impostos valores culturais e também possibilidades de vida que transformaram radicalmente o modo como os ruandeses viviam, se entendiam e se relacionavam. Tudo isso proporcionado por um nefasto projeto colonialista.

Essas profundas mudanças trouxeram uma grande insatisfação para a sociedade ruandesa. A legitimidade do domínio Tutsi vai se esvaziando na medida em que alguns costumes são deixados de lado, fazendo com que a dominação sofrida pela população Hutu fique cada vez mais abusiva, sobretudo com o aumento da jornada de trabalho, os castigos físicos e a falta de terras para a produção de seus próprios gêneros agrícolas (NEWBURY, 1997).

Tais condições levaram à maior revolta popular de Ruanda, em que o processo conhecido como a Revolução Hutu de 1959 representou uma grande convulsão social que culminou com expulsão do Mwami, o fim de uma aristocracia e privilégios Tutsis, além de encaminhar a independência do país em 1962, com uma política mais voltada ao Hutu e entendendo o Tutsi como um estrangeiro dentro do território ruandês (DES FORGES, 1999, p. 33). Todo este processo mudaria radicalmente a própria percepção acerca das identidades de Tutsis e Hutus (BERKELEY, 2010, p. 65).

Com a independência de Ruanda frente à Bélgica em 1962, o país passou a construir a sua própria experiência republicana com o Movimento Democrático Republicano - Parmehutu (MDR Pamerhutu), um partido com um discurso voltado para a população Hutu de Ruanda e que elegeu o primeiro presidente do país, Grégoire Kayibanda. (STRAUS, 
2006, p. 183). A influência do MDR Pamerhutu se tornou tamanha que boa parte da estrutura burocrática do país ficou ocupada por membros do partido, principalmente a partir de um discurso que valorizava as cotas raciais para Hutus em uma margem proporcional ao da população, ou seja, algo em torno de $90 \%$ dos cargos públicos deveriam ficar com Hutus indicados pelo MDR Parmerhutu. Esse movimento tornou Ruanda um país que funcionava praticamente como um regime de partido único, já que a margem de manobra e a perseguição a outros partidos ficou bastante apertada.

No entanto, a frustração com os resultados da independência por parte de alguns setores da população, somada à falta de controle que o presidente Grégoire Kayibanda possuía no meio rural, fez com que o chefe das forças armadas, General Juvenal Habyarimana, comandasse um golpe de Estado que dissolveu a Primeira República, com a inauguração da Segunda República Ruandesa e sua própria nomeação como novo presidente do país (STRAUS, 2006, p. 192).

A partir de 1975, o General Habyarimana instituiu o regime de partido único em Ruanda, com o Movimento Revolucionário Nacional pelo Desenvolvimento (MRND), em que todos os ruandeses eram membros obrigatórios desde o nascimento, de modo que o Estado ruandês e a própria sociedade tornaram-se um só.

A grande repressão às múltiplas oposições que o presidente Habyarimana enfrentava (desde oposições regionais como de países vizinhos), somadas à sua falta de articulação, fez com que apenas em 1990 algum movimento oposicionista conseguisse ameaçar o poder consolidado do MRND. Em primeiro de outubro de 1990 a Frente Patriótica Ruandesa (RPF, da sigla em francês), uma organização armada formada por oposicionistas (em sua maioria Tutsis) invadiu o território ruandês a partir de Uganda, o que acabou como um grande pretexto para as forças militares ligadas ao MRND perseguirem diferentes oposicionistas como se fossem colaboradores da RPF (STRAUS, 2006, p. 25).

Por outro lado, somada às fragilidades econômicas que o país atravessava, essa repressão forçou o MRND a negociar uma abertura política para o multipartidarismo, o que ocorreu em junho de 1991. A partir de tal abertura, foram criados o Partido Liberal (PL), o Partido da Social Democracia (PSD) e o Partido da Democracia Cristã (PDC), mas o partido que mais conseguiu ter força neste primeiro momento foi o Movimento Democrático Republicano (MDR), que aclamava por uma herança histórica com o movimento do MDRParmehutu e sua política centrada e voltada para a população Hutu de Ruanda. É importante destacar que Jean-Paul Akayesu se tornou Burgomestre de Taba pelo MDR, no qual era um dos coordenadores locais.

Mesmo com a abertura política, a Frente Patriótica Ruandesa continuou como uma oposição clandestina e posta como ilegal, com o objetivo declarado de derrubar o governo de Habyarimana a partir de incursões armadas no país, levando a uma desgastante guerra civil e a um clima de desconfiança e insegurança por boa parte da população ruandesa (STRAUS, 2006, p. 29). Tal contexto ficava ainda mais tenso com a ampla propaganda que se desenvolvia contra a oposição e a formação de milícias armadas por parte da juventude de alguns partidos políticos, como é o caso da Interahamwe ${ }^{106}$, ligada ao MRND, e a Impuzamugambi ${ }^{107}$, ligada à Coalizão pela Defesa da República (CDR). ${ }^{108}$

A propaganda anti-Tutsi, colocando-o como uma figura traiçoeira e que merecia um constante estado de atenção (FONSECA, 2014, p. 59), foi levada a cabo pelos meios de comunicação, como é o caso da Revista Kangura, de Hassan Ngeze - membro fundador do CDR -, e também a Radio Television Libre dês Milles Collines (RTLM), coordenada por Léon Mugesera, um dos líderes da Interahamwe e membro do MRND.

\footnotetext{
106 Do kinyarwanda: "aqueles que trabalham juntos" ou "aqueles que atacam juntos". Grupo paramilitar da MRND, do início da década de 1990, que corroborou com o governo de Habyarimana e com o genocídio.

107 Do kinyarwanda: "aqueles que têm o mesmo objetivo". Grupo paramilitar da CDR, do início da década de 1990, que corroborou com o governo de Habyarimana e com o genocídio.

108 A Coalizão pela Defesa da República (CDR) foi um partido político formado em 1992 a partir de hutus extremistas.
} 
No dia 6 de abril de 1994, após a morte do General Habyarimana com a queda de seu avião presidencial, teve início o genocídio de Ruanda, quando o exército ruandês e as milícias pró-governo começaram a construir bloqueios ao redor e dentro da capital Kigali, de modo a encontrar e assassinar Tutsis e também Hutus que eram considerados moderados (um Hutu moderado poderia ser simplesmente aquele que era favorável a um acordo de paz com a oposição ou que se relacionava com Tutsis).

Apesar de o conflito vitimar tanto Tutsis como Hutus, existem diversas evidências que apontam que as vítimas primárias do genocídio eram os Tutsis, sem poupar nem mulheres nem crianças. O fim oficial do conflito se deu em 18 de julho de 1994, quando a Frente Patriótica Ruandesa ocupou toda a capital Kigali, encerrando um genocídio que assassinou entre 500 mil e um milhão de ruandeses.

\section{Um estudo de caso: o Burgomestre Jean-Paul Akayesu}

Jean-Paul Akayesu, nascido em 1953, se tornou Burgomestre da Comuna de Taba (ligada à prefeitura de Gitarama ${ }^{109}$ ) em abril de 1993 e ficou no cargo até próximo o final do genocídio de Ruanda, em junho de 1994. A sua eleição ao cargo foi pelo Movimento Democrático Republicano (MDR), partido dissidente do tradicional MRND, formado a partir da abertura política e do fim do sistema de partido único, em que o MRD constituía uma ala crítica ao poder central ruandês por ser entendido como fraco ao enfrentar alguns problemas. (ICTR, 1998, p. 38).

O processo eleitoral vitorioso por Jean-Paul Akayesu foi a primeira eleição aberta para Burgomestre nas comunas de Ruanda, e o resultado obtido por Akayesu se deu muito devido a sua inserção em sua comuna, na qual exercia a função de professor, sendo muito bem quisto pelo restante da comunidade. Segundo o documento do ICTR, Akayesu "era bem conhecido e uma figura popular na comunidade local"110 (ICTR, 1998, p. 37.), "era considerado um homem de alta moral, inteligência e integridade, possuindo as qualidades de um líder, o qual parecia possuir a confiança da comunidade local"111 (ICTR, 1998, p. 38.), além de ser também ideologicamente alinhado e bem inserido nas novas correlações de poderes políticos que se redesenhavam no território de Ruanda.

Dentre suas principais funções como Burgomestre na Comuna de Taba, Jean-Paul Akayesu possuía funções administrativas na realocação de recursos e também de pessoal, tendo o poder de contratar e demitir funcionários públicos de acordo com as necessidades da comuna ou também de favores políticos (ICTR, 1998, p.41). Possuindo o controle da polícia comunal, outra função dos Burgomestres de Ruanda era a manutenção da ordem e a mediação de conflitos em seu território. A polícia comunal não se constituía como uma polícia militar, era formada apenas de civis, e Akayesu "tinha autoridade máxima sobre ela e inteiramente responsável por sua organização, funcionamento e controle"112 (ICTR, 1998, p. 42).

Outro ponto importante que envolvia os Burgomestres de Ruanda era a sua relação com a Gendarmerie Nationale, que era a Polícia Militar das áreas rurais de Ruanda. Composta pelos gendarmes, constituía-se como a maior força militar do país (LIPPI, 2014, p. 295) e uma espécie de força nacional que deveria manter a ordem pública quando requisitada. Apenas os prefeitos tinham o poder de requerer a intervenção da Gendarmerie e não os Burgomestres. Por outro lado, no decorrer da ação dos gendarmes, o Burgomestre poderia se configurar como a autoridade diante destes frente a uma emergência nacional ou em tempos de guerra; o que não é muito claro na legislação ruandesa, tendo em vista que

\footnotetext{
109 Gitarama é uma das 11 municipalidades em que Ruanda era dividida, as quais possuíam diversas comunas, que, por sua vez, também eram divididas em setores.

110 No original: "Was a well-known and popular figure in the local community." (Tradução livre).

111 No original: "Was considered a man of high morals, intelligence and integrity, possessing the qualities of a leader, who appeared to have the trust of the local community." (Tradução livre).

112 No original: "Has ultimate authority over it and entirely responsible for its organization, functioning and control." (Tradução livre).
} 
tais apontamentos são baseados em um decreto de 1959 expedido ainda pelas autoridades coloniais belgas (ICTR, 1998, p. 43-44), logo após a Revolução Hutu de 1959.

Porém, os poderes de um Burgomestre ruandês vão além daqueles poderes que the cabem pela legislação local, já que "em Ruanda, o Burgomestre é a figura mais poderosa da comuna. Sua autoridade de fato na área é significativamente maior do que aquela que está sobre ele de jure"113 (ICTR, 1998, p. 39, grifo do original). Essa diferença entre o poder de facto e de jure que os Burgomestre possuíam é bastante significativo para entendermos a participação de Jean-Paul Akayesu e de figuras similares no decorrer do genocídio de 1994, tendo em vista que muitas de suas ações no decorrer do genocídio se davam a partir dos seus poderes, que extrapolavam a função meramente política, englobando também seu papel social frente à população que representava.

Segundo relatos de testemunhas ${ }^{114}$ recolhidos pelo ICTR: "o Burgomestre era considerado como o 'pai' de toda a população, cuja cada ordem seria respeitada"115 (ICTR, 1998, p. 45); "as pessoas normalmente seguiriam as ordens da autoridade administrativa, o Burgomestre, mesmo se essas ordens fossem ilegais ou injustas"116 (ICTR, 1998, p. 45); "as pessoas não poderiam desobedecer as ordens do Burgomestre"117 (ICTR, 1998, p. 45). Tal autoridade e respeito diante da população local fazia com que o poder de facto do Burgomestre tivesse um peso decisivo na vida política local.

Em depoimento para o ICTR, Alison DesForges (pesquisadora fundamental acerca da história ruandesa) afirmou que os Burgomestres adquiriram tal poder e se tornaram a autoridade mais importante para a população comum de uma dada comuna. Segundo DesForges, poderíamos inclusive fazer uma correlação direta entre esse poder atribuído aos Burgomestres com os poderes que os chefes locais possuíam em tempos pré-coloniais (ICTR, 1998, p.45).

Precisamos destacar que esse poder que o chefe local possuía dentro das sociedades domésticas africanas em tempos pré-coloniais era de suma importância para a coesão das comunidades, ainda mais em um microcosmo dos povos africanos, conforme apontam os intelectuais Joseph Ki-Zerbo, de Burkina Faso, e Boubou Hama, do Níger (2010). Segundo Ki-Zerbo e Hama, os chefes africanos não possuiriam as características de déspotas, como muitas vezes é entendido pelo mundo ocidental, mas seriam um elemento central da sociedade africana, em que "a concepção africana de chefe dá a este último um espaço exorbitante na história dos povos dos quais ele literalmente encarna o projeto coletivo" (HAMA; KI-ZERBO, 2010, p.29). Tais características de poder dos chefes locais acabaram permanecendo culturalmente em muitas sociedades africanas, o que nos ajuda inclusive a refletir de uma maneira não enviesada acerca de alguns políticos africanos que passam anos e até décadas no poder.

No decorrer do genocídio de 1994, a Comuna de Taba administrada por Akayesu ganhou destaque devido ao seu alto engajamento com os crimes cometidos, em que o nível de assassinatos e outras formas de violência foram considerados excessivos. Estima-se que pelo menos 2000 Tutsis foram assassinados na comuna de Taba entre 7 de abril de $1994 \mathrm{e}$ o fim do mês de junho de 1994 (ICTR, 1998, p. 10).

Durante esse processo, a figura do Burgomestre Jean-Paul Akayesu foi posta como um elemento central no decorrer do genocídio na região, tendo em vista que não só não tentou impedir a execução e continuidade, como também colaborou diretamente para que muitos crimes ocorressem, sendo responsável direto pela coordenação, pela supervisão e até pela execução de crimes na região de Taba.

\footnotetext{
${ }^{113}$ No original: "His 'de facto' authority in the area is significantly greater than that which is upon him de 'jur'e'." (Tradução livre).

114 Tais testemunhas possuem a identidade preservada no decorrer do processo.

115 No original: "The bourgmestre was considered as the 'parent' of all the population whose every order would be respected." (Tradução livre).

116 No original: "The people would normally follow the orders of the adminstrative authoroty, the bourgmestre, even if those orders were ilegal or wrongful." (Tradução livre).

117 No original: "The people could not disobey the orders of the bourgmestre." (Tradução livre).
} 
Após o término do genocídio, Jean-Paul Akayesu fugiu para a Zâmbia, onde foi preso em 1995. O ex-Burgomestre de Taba foi julgado pelo ICTR, acusado de crimes contra a humanidade, incitação para cometer genocídio e genocídio. Akayesu foi condenado em 1998 a prisão perpétua e cumpre atualmente a sua pena em uma prisão do Mali. O processo do ICTR contra Jean-Paul Akayesu teve uma grande e importante repercussão internacional, tendo em vista que foi a primeira condenação pelo crime de genocídio em Ruanda, além de em seu processo também constar a relação direta do crime de estupro enquanto uma forma de executar o crime de genocídio, criando uma jurisprudência que é bastante estudada pela área do Direito. ${ }^{118} \mathrm{~A}$ questão do estupro e da mulher no genocídio de Ruanda também é bem dimensionada pelo dramaturgo do Chade Koulsy Lamko, em sua obra La phalène des Collines (2000), em que o autor da voz à vítima Thérèse Mukandori, que foi brutalmente assassinada e estuprada, e, no romance, renasce como uma borboleta.

A partir de seu processo e julgamento pelo ICTR, intitulado The prosecutor versus Jean-Paul Akayesu - Case No. ICTR-96-4-T, podemos dimensionar melhor a sua participação no genocídio e refletir sobre a participação de políticos da esfera local no decorrer do genocídio em 1994, principalmente a partir dos diferentes testemunhos existentes nos relatórios do processo.

Após a queda do avião presidencial do General Juvenal Habyarimana, no dia 4 de abril de 1994, o genocídio não tardou a chegar até a Comuna de Taba, então administrada pelo Burgomestre Jean-Paul Akayesu. É importante destacar, conforme estudado por Scott Straus (2006), que o genocídio não ocorreu de uma maneira coesa em todas as regiões de Ruanda, pois em alguns locais o genocídio foi muito mais intenso, como é o caso Capital de Kigali City e de comunas das prefeituras de Kigali Rural e Kibungo, em que os assassinatos começaram horas depois da notícia da queda do avião presidencial, enquanto outras regiões chegaram a resistir ao genocídio, como é o caso de comunas nas prefeituras de Byumba, Ruhengeri, entre outras (STRAUS, 2006, p. 56).

No caso da prefeitura de Gitarama, onde se localiza a Comuna de Taba, o genocídio não começou rapidamente, tardando algo em torno de dez dias para ter início; mas marcou a primeira quinzena do genocídio, a qual foi a mais crítica, tendo em vista que algo em torno de $75 \%$ dos assassinatos ocorridos no genocídio de Ruanda ocorreram entre os dias 10 e 21 de abril de 1994 (STRAUS, 2006, p. 57). No caso de Taba, não foi diferente de outras comunas de Gitarama, pois muitas testemunhas colocam as ações genocidas vinculadas a Akayesu como ocorrendo por volta do dia 19 de abril de 1994.

Segundo testemunhas ouvidas pelo ICTR:

Por volta de 19 de abril de 1994, antes do amanhecer, no setor de Gishyeshye, Comuna de Taba, um grupo de homens, um dos quais se chamava Fraçois Ndimubanzi, matou um professor local, Sylvere Karera, porque ele foi acusado de se associar com a Frente Patriótica Ruandesa (RPF) e por conspirar para matar Hutus. Embora pelo menos um dos agressores tenha sido entregue a Jean-Paul Akayesu, ele não tomou medidas para prendê-lo. ${ }^{119}$ (ICTR, 1998, p. 11).

O início do genocídio na Comuna de Taba é marcado em um primeiro momento pela omissão do Burgomestre Jean-Paul Akayesu frente ao assassinato do professor Sylvere Karera por François Ndmubanzi, em que, mesmo conhecendo o acusado, Akayesu não pareceu realizar esforços para exercer a sua própria função de conter o assassino, conduta

\footnotetext{
118 Para um maior aprofundamento sobre a relação do estupro e o genocídio, recomendo a obra: LIPPI, Camila Soares. O estupro enquanto genocídio no Tribunal Penal Internacional Para Ruanda: um estudo do caso Akayesu, Espaço Jurídico Jounaul of Law, Chapecó, v. 15, n. 2, p. 287-314, jul./dez. 2014.

119 No original: "On or about 19 april 1994, before dawn, in Gishyeshye sector, Taba communu, a group of men, one of whom was named Fraçois Ndimubanzi, killed a local teacher, Sylvere Karera, because he was accused of associating with the Rwandan Patriotic Front (RPF) and plotting to kill Hutus. Even though at least one of the perpetrators was turned over to Jean-Paul Akayesu, he failed to take mensures to have him arrested." (Tradução livre).
} 
a qual se repetiu no decorrer de todo o genocídio, em que "nunca tentou impedir o assassinato de Tutsis na comuna, de forma alguma, ou pediu assistência de autoridades regionais ou nacionais para acabar com a violência."120 (ICTR, 2018, p. 10).

A omissão de Jean-Paul Akayesu não foi por acaso, mas sim devido ao seu próprio alinhamento com as ações genocidas que começavam a apontar no horizonte de Taba, o que é evidente a partir do momento que o Burgomestre começou a assumir mais as responsabilidades por coordenar as tarefas com caráter genocida. Segundo testemunhas ouvidas pelo ICTR (1998):

Na manhã de 19 de abril de 1994, após o assassinato de Sylvere Karera, Jean-Paul Akayesu liderou uma reunião no setor de Gishyeshye em que ele confirmou a morte de Sylvere Karera e incitou a população a eliminar cúmplices da RPF, o que foi entendido pelos presentes como significando tutsis. [...] o assassinato de tutsis em Taba começou logo após a reunião. ${ }^{121}$ (ICTR, 1998, p. 11).

O encontro organizado por Jean-Paul Akayesu no setor de Gishyeshye se tornou um marco importante para as ações que foram tomadas nos dias subsequentes, tendo em vista que alguns parâmetros de perseguição passaram a ser estabelecidos e assumidos pelo Burgomestre de Taba, como é o caso de "conduções de buscas de casa em casa"122 (ICTR, 1998, p.11), em que "durante essas buscas, os residentes, incluindo a Vítima V, foram interrogados e agredidos com rifles e bastões na presença de Jean-Paul Akayesu"123 (ICTR, 1998, p. 11), com o intuito de conseguir "informações sobre a atividades de Tutsis que ele estava procurando"124 (ICTR, 1998, p. 11).

É possível observar nas citações supracitadas que, na busca por vítimas, existia um padrão que realizava correlações entre a população Tutsis ruandesa e a oposição armada da Frente Patriótica Ruandesa, a expressar-se: tanto no assassinato do professor Sylvere Karera; como no encontro organizado por Akayesu conclamando a população a eliminar os cúmplices da RPF, entendidos como tutsis; além de também estar presente nas falas que indicavam os motivos das buscas de casa em casa para procurar informações a respeito de alguns Tutsis específicos.

Essa correlação entre a Frente Patriótica Ruandesa e a população Tutsi foi muito frequente no decorrer da Guerra Civil ruandesa e do genocídio em 1994, em que muitos Hutus afirmavam não estar perseguindo Tutsis, mas sim os membros e os simpatizantes da RPF (FONSECA, 2013, P. 63). No entanto, esse discurso era normalmente complementado com a observação que todos os Tutsis eram membros ou simpatizantes da RPF, e com isso todos os Tutsis deveriam ser perseguidos.

Tais argumentos foram amplamente difundidos no início da década de 1990 pelos meios de comunicação ligados ao governo de Juvenal Habyarimana, como é o caso da Revista Kangura e o Radio Television Libre dês Milles Collines (RTLM) ${ }^{125}$, conforme podemos observar no seguinte trecho retirado da Revista Kangura: "Você entende que a FPR que nos atacou era composta por aquelas pessoas que têm origem dos Tutsis que

\footnotetext{
120 No original: "never attempted to prevent the killing of Tutsis in the commune in any way or called for assistence from regional or national authorities to quell the violence." (Tradução livre).

121 No original: "The morning of April 19, 1994, following the murder of Sylvere Karera, Jean-Paul Akayesu led a meeting in Gishyeshye sector at wich he sanctioned the death of Sylvere Karera and urged the population to eliminate accomplices of the RPF, wich was understood by tohse presentes to mean Tutsis. (...) the killing of tutsis in Taba began shortly after the meeting." (Tradução livre).

122 No original: "conducted house-to-house seacrhes." (Tradução livre).

123 No original: "during these searches, residentes, including Victim V, were intorregoted and beaten with rifles and stickes in the presence of Jean-Paul Akayesu." (Tradução livre).

124 No original: "information about the activities of the tutsis he was seeking." (Tradução livre).

125 Para mais informações ver Fonseca (2013).
} 
fugiram em 1959, aqueles que nos atacaram antes de 1967. Assim, eles se organizaram e nomearam-se como FPR." ${ }^{126}$ (ICTR, 2003, p. 122).

Esse discurso de perseguição a todos os Tutsis, além de possuir algumas variáveis, nem sempre era concretizado na prática, pois, no decorrer do genocídio em Ruanda, ocorreram perseguições mais específicas a certas categorias da sociedade civil ruandesa, que foram organizadas a partir de listas de pessoas que deveriam ter prioridade nas ações de buscas e assassinatos. O próprio Burgomestre Akayesu teve essa função de nomear Tutsis que deveriam ser perseguidos e mortos, conforme aponta o documento da ICTR:

Na mesma reunião no setor de Gishyeshye em 19 de abril de 1994, JeanPaul Akayesu nomeou pelo menos três proeminentes tutsis - Ephrem Karangwa, Juvénal Rukundakuvuga e Emmanuel Sempabwa - que deveriam ser mortos por causa de suas alegadas relações com o RPF.127 (ICTR, 1998, p.11).

Além de ser evidente novamente a já citada relação com a Frente Patriótica Ruandesa, é possível observar que os Tutsis perseguidos em um primeiro momento (ou enquanto prioridade) eram Tutsis tidos como proeminentes e que possuíam alguma influência frente à sociedade, como o caso em que "Jean-Paul Akayesu ordenou a população local e a milícia para matarem intelectuais e pessoas influentes"128 (ICTR, 1998, p. 12). Neste caso, assim como no já citado do professor Sylvere Karera, "cinco professores da escola secundária de Taba foram assassinados"129130 (ICTR, 1998, p. 12.), mas desta vez com instruções diretas do Burgomestre.

A luta por espaços em setores da educação e de formação de opinião pública, resultando em assassinatos e perseguição de professores e intelectuais, é relativamente comum e sensível na história ruandesa. Desde a Revolução Hutu de 1959, passando por tensões das repúblicas ruandesas, ocorreram protestos e até atos de violência contra Tutsis que ocupavam cargos em escolas e universidades. Essas tensões seriam provenientes do fato de que a maioria dos professores possuíam a identidade étnica de Tutsis, os quais eram acusados por radicais de favorecer apenas um determinado grupo étnico ${ }^{131}$ (STRAUS, 2006, p. 186).

A disputa pelo setor educacional é expressa inclusive no documento dos "Dez mandamentos hutus", publicado pela primeira vez pela revista Kangura em 1991, em que o setor educacional tinha uma preocupação específica expressa no "mandamento 6", que afirma: "6. No setor educacional, (pupilos, estudantes, professores) devem ser da maioria hutu"132 (ICTR, 2003, p. 45); e se segue de uma sequência de argumentos que enumeram setores fundamentais para o domínio dos Hutus, ao lado das forças armadas e de produções estratégicas da economia.

É importante notar também que boa parte dos assassinatos ordenados por JeanPaul Akayesu foram executados em frente ao Bureau Communal de Taba, ou seja em frente ao prédio da repartição pública da comuna, o que evidencia o grau de autoridade posta naqueles que estavam no poder em Taba, como se esses fossem os mandantes e legitimassem a ação dos assassinos.

\footnotetext{
${ }^{126}$ No original: "You understand that the RPF that attacked us is made of those people, has its origin in those Tutsis who fled in 1959, those who attacked us until 1967. So, they got organized and named themselves RPF." (Tradução livre).

127 No original: "at the same meeting in Gishyeshye sector on April 19, 1994, Jean-Paul Akayesu named at least three prominent Tutsis - Ephrem Karangwa, Juvénal Rukundakuvuga and Emmanuel Sempabwa - who had to be killed because of their alleged relationships with the RPF." (Tradução livre).

128 No orginal: "Jean-Paul Akayesu ordered the local people and militia to kill intelectual and influential people

129 No original: five teachers from the secondary schol of taba were killed." (Tradução livre).

130 Segundo o documento, os professores mortos foram Theogene, Phoebe Uwineze e seu noivo (de nome desconhecido), Tharcisse Twizeyumuremye e Samuel (ICTR, 1998, p. 12).

${ }_{131}$ Como ocorrido nos chamados "massacres étnicos de 1962-64" e "expurgos de 1973".

132 No original: "6. In the Education sector, (pupils, students, teachers) must be in the majority Hutu." (Tradução livre).
} 
Em alguns casos, as vítimas eram conduzidas até os Burgomestres da respectiva comuna para que estes dessem uma espécie de veredicto final sobre o fim que deveria levar um determinado suspeito ou procurado. O próprio Akayesu ordenou e comandou uma série de assassinatos. Esse papel do Burgomestre é evidente inclusive no seguinte trecho transcrito de uma transmissão de rádio da RTLM:

Portanto Gahigi, uma vez na frente dos microfones, por favor, explique para a população que arma bloqueios que todos aqueles que têm nariz pequeno, magrelos, com a pele mais clara não é necessariamente um Tutsi. Caso contrário, você pode achar que nós, os Hutus, estamos matando outros Hutus por confundi-los com os Tutsis, por Inyenzi. Aonde nós iríamos assim? Você prende alguém e pede seu cartão de identificação. Você descobre que ele é um Hutu. Se você não entender, vá ver um Conseiller e pergunte a ele, vá ver o Burgomestre e pergunte a ele. Na minha opinião, isso deve ser uma prioridade e tem que ser absolutamente respeitado nos bloqueios de estrada. ${ }^{133}$ (ICTR, 2003, p. 256)

A partir das palavras transcritas da transmissão acima, vemos que, diante de um impasse que envolva a dúvida sobre a origem étnica de um determinado indivíduo ruandês, fosse por questões físicas ou não, aqueles que poderiam tirar o impasse e dar a palavra final sobre o destino de alguém que estivesse preso ou cativo eram as autoridades locais dos conselheiros locais e também do Burgomestre. Sua palavra e ordem era a que maior peso e validade tinha diante do contexto engendrado em Ruanda.

\section{Considerações finais}

No decorrer do artigo, pudemos observar que os políticos locais, mais especificamente os Burgomestres, eram postos como a liderança mais importante e imediata dentro de um microcosmo de determinada comuna ou de seus pequenos setores, sendo bastante respeitados e obedecidos pela população local. Essa autoridade e respeitabilidade por parte dos Burgomestres pode ser entendida como uma herança cultural pré-colonial vinda da sociedade Banyarwanda, como apontou DesForges, mas não parece suficiente para e própria execução do genocídio em 1994.

Durante o genocídio, o poder dos Burgomestres, como o de Jean-Paul Akayesu, se constituiu com uma autoridade bastante elevada, sendo possível que este não tomasse medidas frente ao assassinato do professor Silvere Karera; organizasse encontros para ajudar na coordenação do genocídio, como o fez no setor de Gishyeshye; coordenasse buscas por Tutsis específicos, como o indicado pela Vítima V; expedisse listas de Tutsis que deveriam ser perseguidos e assassinados, como foi o caso de Ephrem Karangwa, Juvénal Rukundakuvuga e Emmanuel Sempabwa, além dos professores Theogene, Phoebe Uwineze e seu noivo (de nome desconhecido), Tharcisse Twizeyumuremye e Samuel; e também por legitimar uma série de outros assassinatos na Comuna de Taba.

Podemos refletir que tamanho poder foi possível também devido a um vácuo de autoridade deixado pelo próprio contexto histórico ruandês, em que pela primeira vez a autoridade do Burgomestre não estava diretamente vinculada a uma indicação do próprio presidente, mas sim a partir de eleições locais, o que deu maior força aos Burgomestres diante da população local.

Esse vácuo de poder também foi corroborado pelo clima de insegurança e suspeita acerca da oposição armada da Frente Patriótica Ruandesa, em que, dentro de um contexto

\footnotetext{
133 No original: "Therefore Gahigi, once in front of the microphone, please explain to the population manning roadblocks that all those having a small nose, slender, with a light skin are not necessarily Tutsis. Otherwise, you will find that we, the Hutus, are killing other Hutus mistaking them for Tutsis, for Inyenzi. Where would we go like this? You arrest someone and ask him his ID card. You find that he is a Hutu. If you do not understand, go and see the Conseiller and ask him, go and see the bourgmestre and ask him. In my view, this must be a priority and be absolutely respected on roadblocks." (Tradução livre).
} 
de Guerra Civil e incerteza política, o discurso extremista de associação entre a RPF e os Tutsis encontrou reverberação em parte da população, que foi ainda mais inflamada por figuras como o próprio Burgomestre Akayesu que se dirigia à população local aclamando e coordenando a perseguição e o assassinato de tais sujeitos. Em meio a essa multiplicidade de fatores, não podemos esquecer também da queda do avião presidencial do General Juvenal Habyarimana, pois sua morte colaborou ainda mais para o aumento de poder das autoridades locais no microcosmo da comuna.

\section{Fontes}

ICTR-96-4-T The prosecutor versus Jean-Paul Akayesu.

Transmissão da RTLM, Gaspard Gahigi entrevista Hassan Ngeze, 14 de junho de 1994. In: PROSECTOR V. FERDINAND NAHIMANA, JEAN-BOSCO BARAYAGWIZA AND HASSAN NGEZE: Case No. ICTR-99-52-T/Judgement and setence, dez. 2003, p 256.

Transmissão da RTLM, Gaspard Gahigi entrevista Ferdinand Nahimana, 20 de novembro de 1993. In: PROSECTOR V. FERDINAND NAHIMANA, JEAN-BOSCO BARAYAGWIZA AND HASSAN NGEZE: Case No. ICTR-99-52-T/Judgement and setence, dez.2003, p 122.

REVISTA KANGURA, n. 6, dez.1990. In: PROSECTOR V. FERDINAND NAHIMANA, JEANBOSCO BARAYAGWIZA AND HASSAN NGEZE: Case No. ICTR-99-52-T/Judgement and setence, dez.2003, p 45.

\section{Referências bibliográficas}

BELLUCCI, Beluce. O Estado na África. Revista Tempo do mundo, Brasília, v. 2, n. 3, p. 943, 2010.

BENJAMIN, Walter. Sobre o conceito de História. In: Magia e técnica, arte e política: ensaios sobre literatura e história da cultura. São Paulo: Brasiliense, 1993.

BERKELEY, Bill. The graves are not yet full: Race, tribe and power in the heart of Africa. New York: Basic Book, 2001.

DES FORGES, Alison, "Leave none to tell the story": genocide in Rwanda. New York: Human Rights Watch, 1999.

DIOP, Boubacar Boris. Murambi: the book of bones, Blomington, Indiana University Press, 2006.

FANON, Frantz. Os condenados da terra. Juiz de Fora. Ed. UFJF, 2005.

FONSECA, Danilo Ferreira da. A mídia ruandesa no genocídio de 1994: a relação entre tutsis, Inkotanyis e a Frente Patriótica Ruandesa. Em Tempo de Histórias, Brasília, v. 22, p. 56-77, 2013.

FONSECA, Danilo Ferreira da. África entre classes e etnias: África do Sul (1948-1994) e Ruanda (1959-1994). Saarbrücken: Novas Edições Acadêmicas, 2015.

GOUREVITCH, Philip. Gostaríamos de informá-lo de que amanhã seremos mortos com nossas famílias. São Paulo: Companhia das letras, 2006.

HAMA, Boubou, KI-ZERBO, Joseph. Lugar da história na sociedade africana. In: KI-ZERBO, Joseph. História Geral da África: Metodologia e pré-história da África. Brasília: UNESCO, 2010. Vol. I.

AMKO, Koulsy. La phalene des collines. Butare: Ed. Kuljaama, 2000. 
LIPPI, Camila Soares. O estupro enquanto genocídio no Tribunal Penal Internacional Para Ruanda: um estudo do caso Akayesu. Espaço Jurídico Jounaul of Law, Chapecó, v. 15, n. 2, p. 287-314, jul./dez. 2014.

MAMDANI, Mahmood. When victms become killers: colonislism, nativism and the genocide in Rwanda. Princeton: Princeton University Press, 2002.

NEWBURY, Catharine. Ethnicity and the politics of history in Rwanda. Africa Today, Bloomington, v. 2, n. 44, p. 211-222, 1997.

SHAACK, Beth Van. Engendering genocide: The Akayesu Case before the International Criminal Tribunal for Rwanda. Santa Clara University Legal Studies. Research paper n. 855, jul. 2008.

STRAUS, Scott. The order of the genocide: race, power, and war in Rwanda. Ithaca: Cornell University Press, 2006.

VISENTINI, Luiz D. História da África e dos Africanos. São Paulo: Vozes, 2014.

Recebido em julho de 2018. Aprovado em dezembro de 2018. 